\title{
Comparison of hourly variations of radio refractivity for quiet and disturbed days during dry and rainy seasons at Minna
}

\author{
O. N. Okoro ${ }^{1 *}$, G. A. Agbo ${ }^{1}$,J. E. Ekpe ${ }^{1}$ and T. N. Obiekezie ${ }^{2}$ \\ ${ }^{I}$ Department of Industrial Physics, Ebonyi State University, Abakaliki, Nigeria, P.M.B. 053 \\ ${ }^{2}$ Department of Physics, Nnamdi Azikiwe University, Awka, Nigeria \\ *Corresponding author E-mail: bathonjoku@yahoo.com
}

\begin{abstract}
In principle, the EM wave propagation characteristics during quiet or disturbed air conditions are straightforwardly determined by the state of atmospheric refractivity. Nevertheless, atmospheric refractivity varies in time and space more or less randomly. Therefore the statistics of atmospheric refractivity and related propagation effects are of main interest. This work clearly investigates the major difference between radio refractivity changes for quiet and disturbed days during dry and rainy season for Minna. Radio refractivity values were calculated from measured meteorological parameters (relative humidity, temperature and pressure) at Minna, in 2008. The result showed that, there is a sharp decrease in radio refractivity at the early hour of the day (6:00hr) during dry season, while during rainy season, the sharp decrease occurred at the noon time (13:00hr). The result equally showed that radio refractivity has higher values $\sim 388 \mathrm{~N}$-units during rainy season than during dry season with the highest value of $\sim 318 \mathrm{~N}$-units. This is due to decrease in relative humidity during dry season than during rainy season.
\end{abstract}

Keywords: Disturbed days, Quiet days, Radio refractivity comparison, Storm time.

\section{Introduction}

In design of the radio communication networks, it is important to know the atmospheric radio refractive index (the ratio of the velocity of propagation of a radio wave in free space to the velocity in a specified medium Freeman [6]. The knowledge of refractive index is always required when measurements are made in air Gao [7]. The path of a radio ray becomes curved when the radio wave propagates through the Earth atmosphere by reason of the variations in the atmospheric refractivity index along its trajectory [6, 2]. Refractivity of the atmosphere affects not only the curvature of the radio ray path but gives some insight into the fading phenomenon [6]. The anomalous electromagnetic wave propagation can be a problem for radars because the variation of the refractive index can induce loss of radar coverage Norland [10]. In practice, the propagation conditions are more complicated in comparison with the conditions predictable in design of radio system in most cases.

The meteorological conditions have a significant impact on radio wave propagation through atmosphere. The anomalous propagation is due to the variations of the humidity, temperature and pressure that cause variations in the refractive index, Norland [10]. According to Norland [10], even small changes of temperature, humidity and partial water vapor pressure lead to changes in the atmospheric refractive index. Short time variation of the refractive index over line-of-sight paths of approximately $3 \mathrm{~km}$ in mountainous coastal waters using X-band was presented by Norland [9]. Most of the works previously done in the areas of radio refractivity are based on the surface refractivity. Ayantunji et al [1], studied diurnal and seasonal variation of surface refractivity over Nigeria. Agbo et al [5], studied variation of troposheric refractivity at Nsukka in South Eastern Nigeria. In this work, hourly variations of radio refractivity in Minna with Latitude $9^{\circ} 36^{\prime} 50^{\prime \prime} \mathrm{N}$ and Longitude $6^{\circ} 33^{\prime} 24^{\prime \prime} \mathrm{E}$ is investigated using calculated meteorological parameters of hourly record for quiet and disturbed days during dry and rainy seasons for the year 2008 . 


\section{Radio refractivity}

The value of the radio refractive index $n$ is very close to the unit and the changes in this value are very small in the time and in the space. With the aim of making them more notable, the term of radio refractivity $N$ is used, and it is represented by the following expression according to Freeman [6] and ITU-R [9]

$$
N=(n-1) \times 10^{6}
$$

\subsection{Calculation of radio refractivity}

Following the recommendation of ITU-R (2003), radio refractivity can as well be linked with the following expression:

$$
N=77.6 \frac{P}{T}+3.37 \times 10^{5} e / T^{2}
$$

where $T\left({ }^{\circ} \mathrm{C}\right)$ is a temperature, $p(\mathrm{hPa})$ is the atmospheric pressure, $e(\mathrm{hPa})$ is partial water vapor pressure. The refractivity is expressed in $\mathrm{N}$ units.

It was stated by Freeman [6] that expression (2) may be used for all radio frequencies; for frequencies up to $100 \mathrm{GHz}$, the error is less than $0.5 \%$. Equation (2) showed that they are two terms (the "dry term" and the "wet term"). At the sea level, the average value of $N \sim 315$ is obtained. The relationship between the partial water vapor pressure $e$ and the relative humidity $H(\%)$ is:

$$
e=\frac{H e_{S}}{100}
$$

$e_{s}$ is the saturated water vapour pressure at the given atmospheric temperature $t^{\circ} C$, and can be calculated from the following:

$$
e_{s}=6.11 \exp [17.5(T-273.16) /(T 35.87)]
$$

Where

$\mathrm{P}=$ atmospheric pressure $(\mathrm{hPa}), \mathrm{e}_{\mathrm{s}}=$ water vapour pressure $(\mathrm{hPa}) \mathrm{t}=$ absolute temperature $(\mathrm{K})$.

According to ITU-R [9], P and e decease rapidly as the height increase while on the other hand, T decreases slowly as the height increases. Therefore, variation of refractive index horizontally on the lower atmosphere is considerably small when compared to the vertical variation which has a median gradient of about $-40 \mathrm{~N} / \mathrm{km}$ near the in mid altitude and most temperature regions (upper atmosphere) Bean, et al, [3]. Therefore, notable changes are due to the variation in meteorological parameters most especially in the tropical locations Bean et al, [4].

Change in refractive index with height over a given time causes radio waves to curve downwards, and to a degree which depends on the vertical refractivity gradient. Refractive bending causes extension of the radio horizon beyond the optical horizon. This has been noticed to always being the case over Nigeria because of the significant change in climatic condition from the coastal region in the extreme south to the semi-arid region in the extreme North. Hence, the refractivity of the atmosphere will interfere with the curvature of the ray path, but will also provide some insight of fading of radio wave propagation through the atmosphere ITU-R [9]. According to the work conducted by Hassler et al [8], the magnetic variations associated with the auroral electrojet which always moves to the lower latitude having intensities of about $10^{6}$ Ampare during substorm are said to have major influence on radio refractivity. The auroral electrojet during extreme events of solar wind in the atmosphere may cause fields at the Earth surface to be as large as several thousand nonotesla (nT).

\section{Materials and method}

The measurements of meteorological parameters were made in the different time of year and different time of the day at Minna for quiet and disturbed days during dry and rainy seasons in the year 2008. The values of the refractive index have been determined by using measured meteorological data. The values of the refractivity $N$ have been determined by using equation (2). The data of temperature, humidity, and atmospheric pressure were provided by the Centre for Basic Space Science (CBSS). The data which is made up of hourly records of meteorological parameters activities in the atmosphere for quiet and disturbed days during dry and rainy seasons in Minna was obtained with the aid of Vintage 
PRO II Automatic Weather Station. Incorporating the values of the measured parameters in equations (3) and (4), the partial water vapor pressure $e$ was determined.

\section{1 results and discussion}

Fig 1-4 represents the sensitivity of variations of radio refractivity with time for quiet and disturbed days during dry season. From the figures $(1,2$,), the hourly values of radio refractivity plotted at 1-hour interval were observed to posses almost similar characteristics for quiet and disturbed days during dry season and also a different similar characteristics for quiet and disturbed days during rainy season.

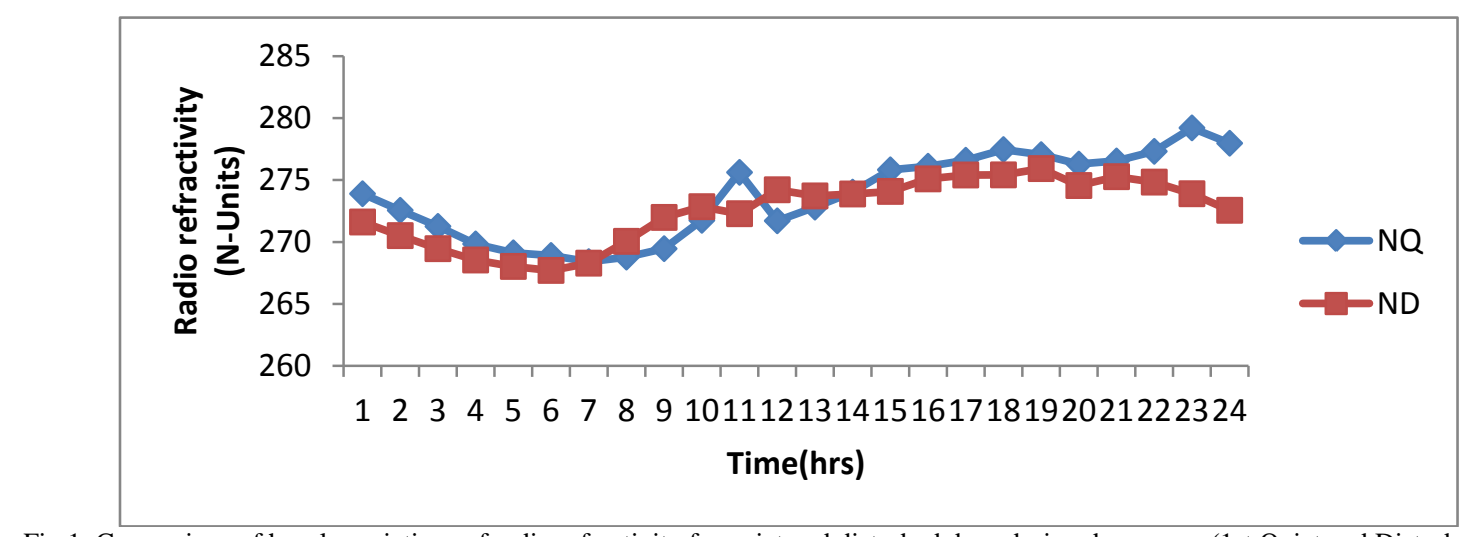

Fig 1: Comparison of hourly variations of radio refractivity for quiet and disturbed days during dry season (1st Quiet and Disturbed days)

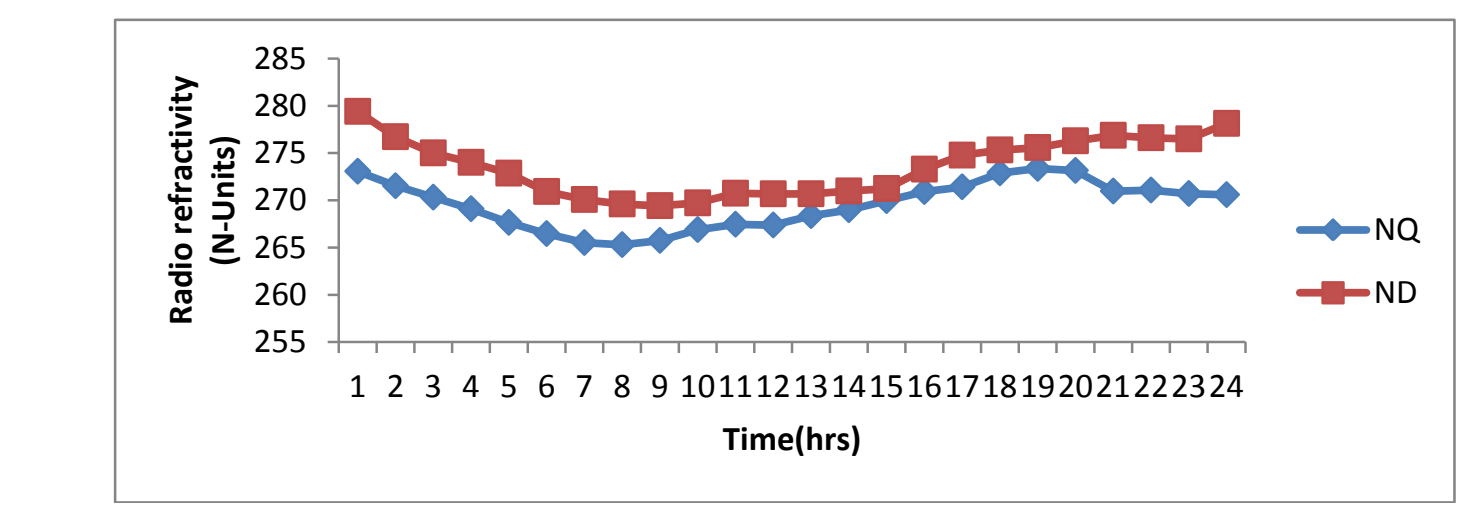

Fig 2: Comparison of hourly variations of radio refractivity for quiet and disturbed daysduring dry season (2nd Quiet and Disturbed days)

In fig 1 and 2, it is observed that a sharp decrease in the value of radio refractivity occurred at about 6:00hr for both quiet and disturbed day plots. This is a time referred to as "storm time" and is a time when energy from solar wind passes to magnetosphere enhancing the influence of ring current (RC) and producing a strong decrease of Dst index which also results in fluctuations in radio refractivity gradient within that time during the first quiet and disturbed days . At the middle of the day till the night side $(11: 00 \mathrm{hr}-24: 00 \mathrm{hr})$, it is clearly noticed that radio refractivity changes progressively with a variations in amplitude for both quiet and disturbed days. This is due to the multipath propagation of electromagnetic field occurring at the night side characterized by relatively fast fluctuations of the meteorological parameters in the atmosphere which eventually resulted in the fluctuations of radio refractivity in the atmosphere as well.

In the 3rd and 4th Quiet and Disturbed days during dry season, the sharp jump noticed at about 14:00hr and 19:00hr and also at $14: 00 \mathrm{hr}$ and $16: 00 \mathrm{hr}$ is caused by the sudden abrupt in the meteorological parameters which eventually caused an abrupt increase in radio refractivity in respond to the variations of atmospheric parameters. In the same way, the values of radio refractivity within the maximum time interval are respectively $\sim 318 \mathrm{~N}$-units and $\sim 278 \mathrm{~N}$-units for the 3rd Quiet and Disturbed days while on the 4th Quiet and Disturbed days, the values of radio refractivity are $\sim 320 \mathrm{~N}$-units and $\sim 294 \mathrm{~N}$-units respectively. 


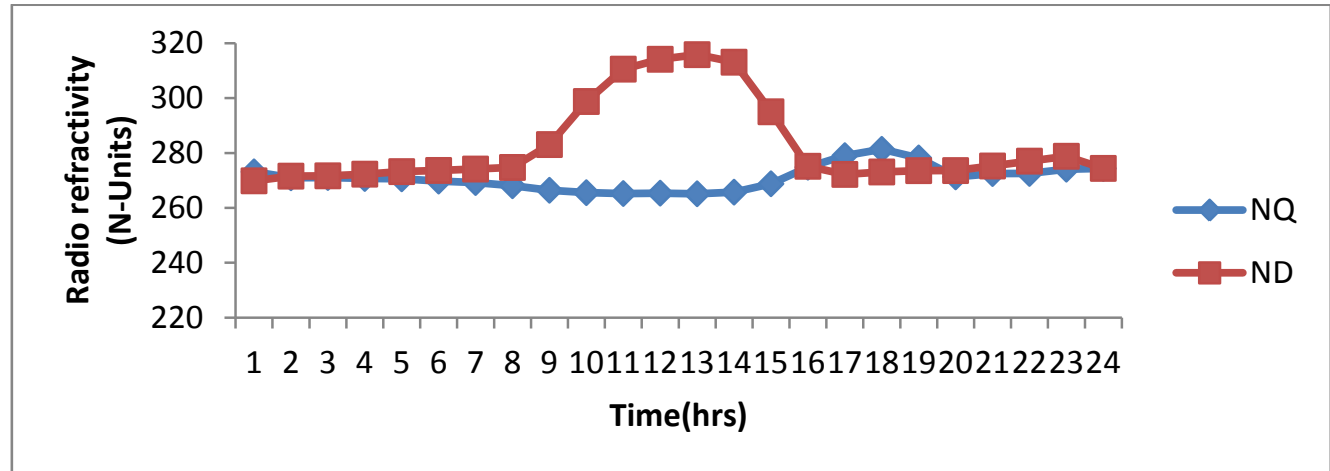

Fig 3: Comparison of hourly variations of radio refractivity for quiet and disturbed days during dry season (3rd Quiet and Disturbed day)

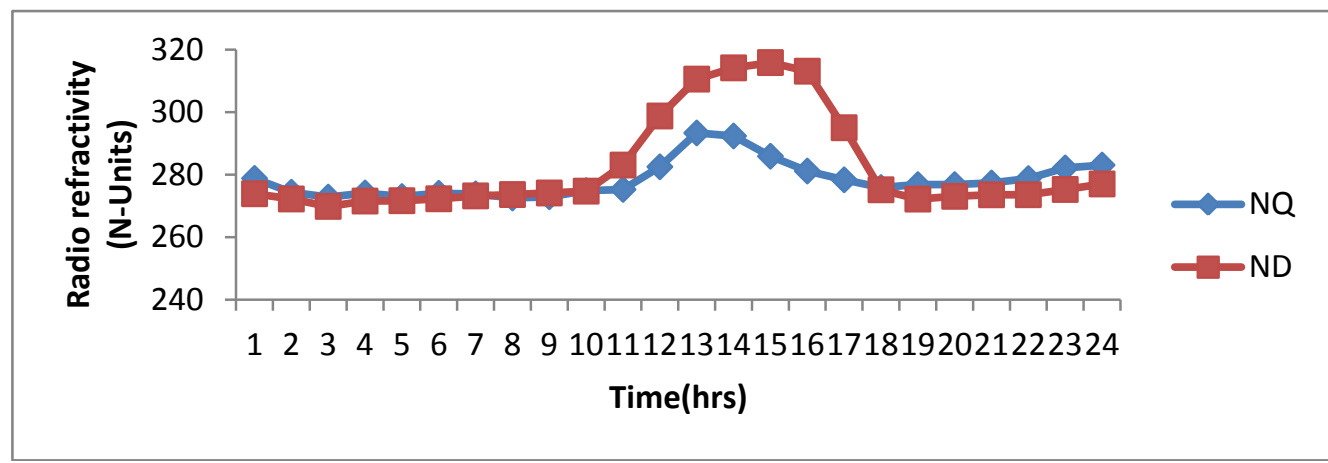

Fig 4: Comparison of hourly variations of radio refractivity for quiet and disturbed days during dry season (4th Quiet and Disturbed days).

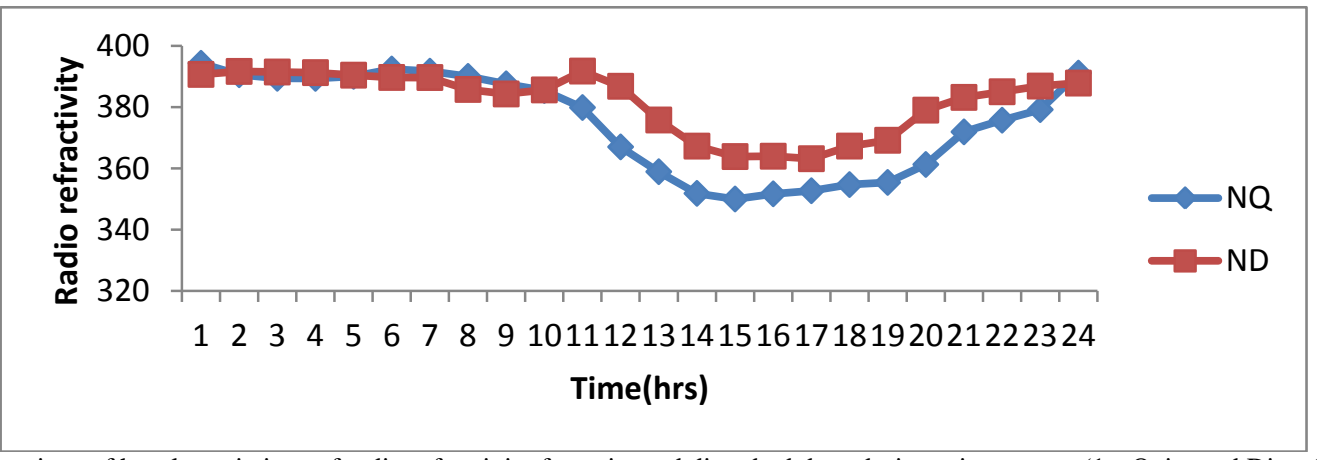

Fig 5: Comparison of hourly variations of radio refractivity for quiet and disturbed days during rainy season (1st Quiet and Disturbed days).

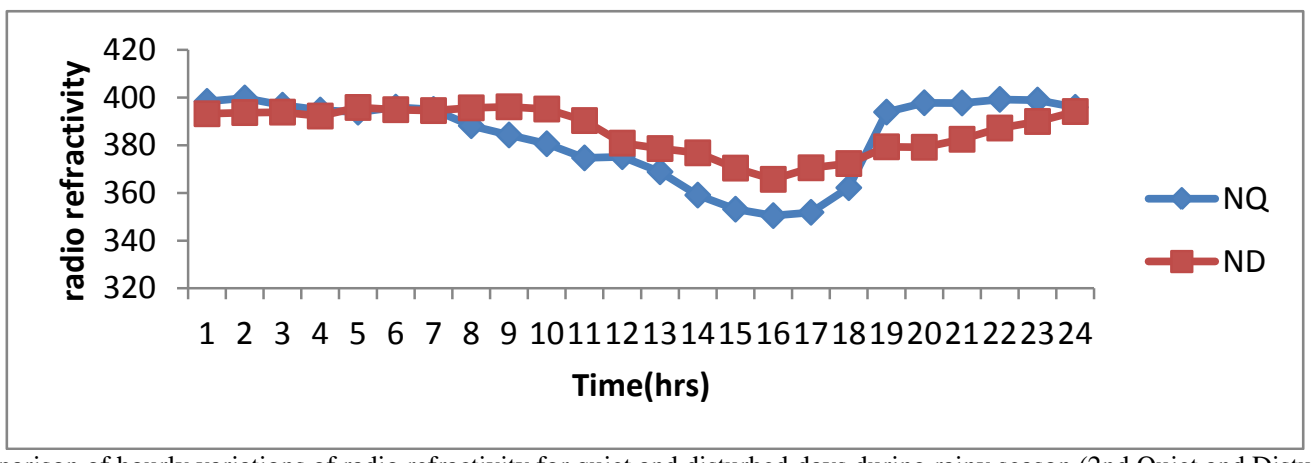

Fig 6: Comparison of hourly variations of radio refractivity for quiet and disturbed days during rainy season (2nd Quiet and Disturbed days). 

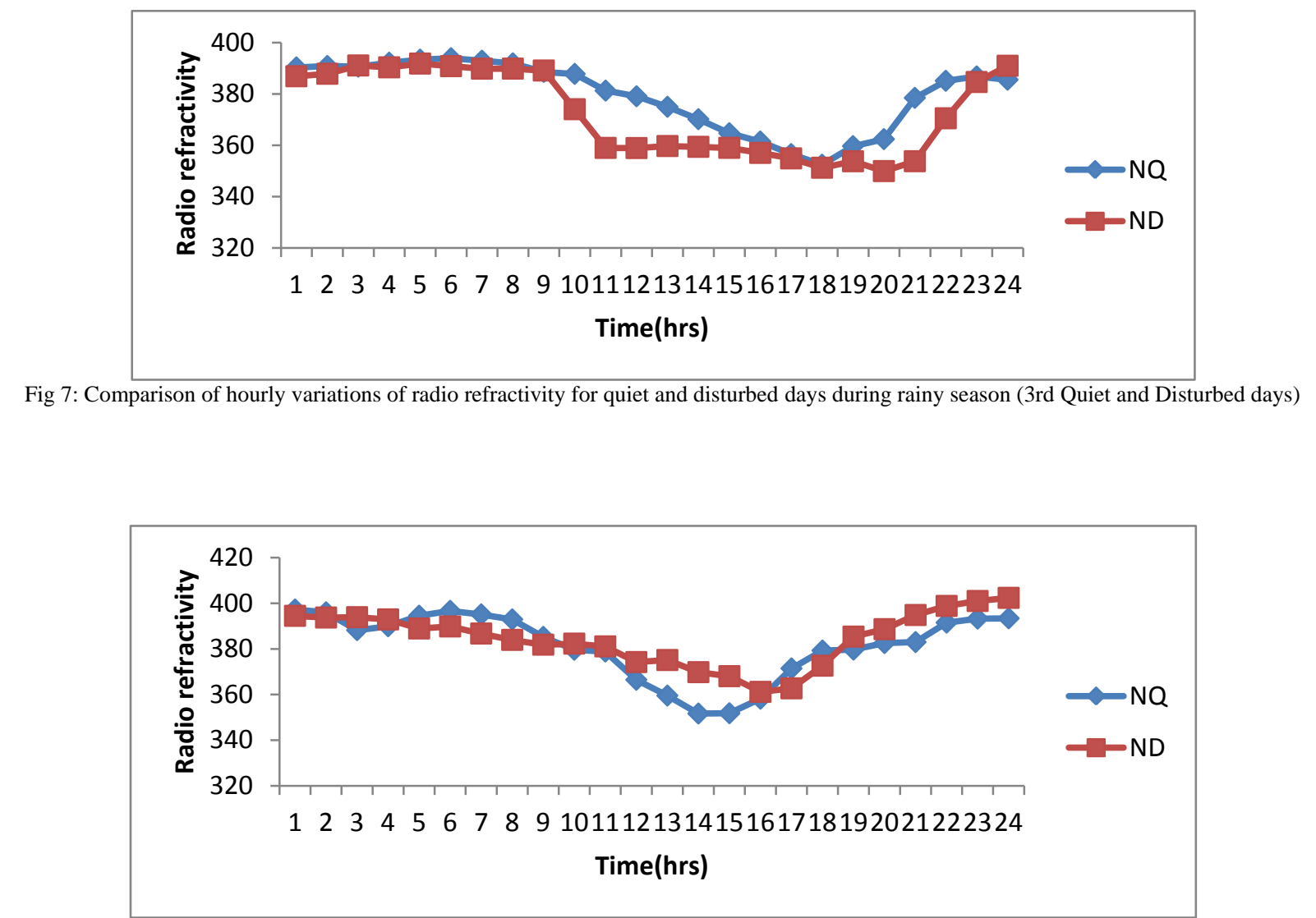

Fig 8: Comparison of hourly variations of radio refractivity for quiet and disturbed days during rainy season (4th Quiet and Disturbed days)

In fig 5-8 (1st-4th Quiet and Disturbed days), it is clearly shown that during early hours of the day when the sun was inactive, radio refractivity displays almost linear changes with time in all the days during rainy season. But at the noon time, there is sharp decrease in radio refractivity within different time range in all the plots. This sharp decreased point which has already been mentioned as "storm time" is notice to occur at different time within the day for both quiet and disturbed days during dry and rainy seasons. During dry season, it occurred at the early hours of the day while during rainy season it occurred at noon day. This decrease has been attributed to the changes in atmospheric parameters within these periods which have contributed to the fluctuations in radio refractivity since radio refractivity is solely dependent on the atmospheric parameters for its efficiency. It is clearly seen as well that radio refractivity has higher values during rainy season for both quiet and disturbed days than during dry season. This is because of the high percentage of relative humidity in the atmosphere within rainy season.

\section{Conclusion}

This work hourly comparison of variation of radio refractivity for quiet and disturbed days during dry and rainy seasons at Minna has actually shown that changes in radio refractivity for quiet and disturbed days during dry season have the same similar characteristics. At the same time, changes in radio refractivity for quiet and disturbed days during rainy season have the same similar characteristics different from that of dry season. These variations in radio refractivity at different time and seasons of the year are due to variations of meteorological parameters in the atmosphere. Finally there has been a clear indication that radio refractivity has higher values during rainy season than it has during dry season at Minna for both quiet and disturbed days.

\section{Acknowledgement}

The authors are highly indebted to various experimental groups, especially the Center for Basic Space Science (CBSS) University of Nigeria Nsukka for providing the meteorological parameters used for this work and to various authors who make their work available for use. 


\section{References}

[1] Ayantunji, B. G., P. N. Okeke and. Urama, J. O, Progress In Electromagnetics Research Vol. 30, (2011) pp $201-222$.

[2] Bean, B. R., Dutton, E.J. Radio Meteorology. Dover Publications Inc., New York, (1968).

[3] Bean, B. R. and G. D. Thayer. Comparison of observed atmospheric radio refraction effects with values predicted through the use of surface weather observations," J. Res. Natl. Bur. Std., Vol. 67, No. 3, (1963) 273-285.

[4] Bean, B. R. and B. A. Cahoon. Correlation of monthly median transmission loss and refractive index profile characteristics, J. Res. N.B.S., Vol. 65, No. 1, (1961) 67-74.

[5] Ekpe. O. E.,.Agbo, G. A., B.G.Ayantunji N.Yusuf and A. C. Onugwu. Variation of Tropospheric Surface Refractivity at Nsukka in South Eastern Nigeria 5(2009) 96-97.

[6] Freeman, R.L. Radio System Design for Telecommunications, 3rd ed., Wiley Interscience, New York (2007).

[7] Gao, J., K. Brewster, M. Xue, A comparison of the radar ray path equation and approximations for use in radar data assimilation, adv. Adv. Atmos. Sci., 23 (2000) 190-198.

[8] Hassler, Donald M., Solar Wind Outflow and the Chromospheric Magnetic Network Science 283 (5403) (1999) 810-813.

[9] ITU-R. The radio refractive index: Its formula and refractivity data (2003) 453-459.

[10] Norland, R., Kraków. Proc Int. Radar Symp, IRS Institute of Electronic Systems, Warsaw University of Technology, Warsaw, 5(221) (2006). 